\title{
Relaxant effects of a hydroalcoholic extract of Ruta graveolens on isolated rat tracheal rings
}

\author{
Luis Águila ${ }^{1,3^{*}}$, Jenny Ruedlinger ${ }^{1}$, Karina Mansilla ${ }^{1}$, José Ordenes ${ }^{1}$, Raúl Salvatici ${ }^{1}$, Rui Ribeiro de Campos ${ }^{4}$ \\ and Fernando Romero ${ }^{1,2}$
}

\begin{abstract}
Background: Ruta graveolens L. (R. graveolens) is a medicinal plant employed in non-traditional medicines that has various therapeutic properties, including anthelmintic, and vasodilatory actions, among others. We evaluated the trachea-relaxant effects of hydroalcoholic extract of $R$. graveolens against potassium chloride (KCl)- and carbachol-induced contraction of rat tracheal rings in an isolated organ bath.

Results: The results showed that the airway smooth muscle contraction induced by the depolarizing agent (KCl) and cholinergic agonist (carbachol) was markedly reduced by $R$. graveolens in a concentration-dependent manner, with maximum values of $109 \pm 7.9 \%$ and $118 \pm 2.6 \%$, respectively (changes in tension expressed as positive percentages of change in proportion to maximum contraction), at the concentration of $45 \mu \mathrm{g} / \mathrm{mL}$ (half-maximal inhibitory concentration $\mathrm{IC}_{50}: 35.5 \mu \mathrm{g} / \mathrm{mL}$ and $27.8 \mu \mathrm{g} / \mathrm{mL}$ for $\mathrm{KCl}$ - and carbachol-induced contraction, respectively). Additionally, the presence of $R$. graveolens produced rightward parallel displacement of carbachol dose-response curves and reduced over $35 \%$ of the maximum smooth muscle contraction.

Conclusions: The hydroalcoholic extract of $R$. graveolens exhibited relaxant activity on rat tracheal rings. The results suggest that the trachea-relaxant effect is mediated by a non-competitive antagonistic mechanism. More detailed studies are needed to identify the target of the inhibition, and to determine more precisely the pharmacological mechanisms involved in the observed biological effects.
\end{abstract}

Keywords: Ruta graveolens, Trachea-relaxant, Plant extract

\section{Background}

Asthma is an airway allergic inflammatory disease characterized by bronchospasms, intermittent chronic inflammation, and airway remodeling $[1,2]$. Meanwhile, chronic obstructive pulmonary disease (COPD) is a progressive pathology characterized by increased airflow restriction [3, 4]. In recent years, efforts to develop more beneficial and safer therapies for these conditions have increased, focusing on prevention rather than treatment of the active diseases $[5,6]$. The current challenge in research is to identify the molecular mediators and mechanisms involved in the pathophysiology of such diseases $[7,8]$.

\footnotetext{
* Correspondence: luis.aguila.paredes@gmail.com

${ }^{1}$ Center of Neurosciences and Peptides Biology (CEBIOR-BIOREN), Faculty of Medicine, University of La Frontera, Temuco, Chile

${ }^{3}$ School of Veterinary Medicine, Unit of Nutrition, and Animal Production,

Faculty of Natural Resources, and Veterinary Medicine, Santo Tomás

University, Temuco, Chile

Full list of author information is available at the end of the article
}

Thus, several pharmacological studies of natural products capable of relaxing the airway smooth muscle to improve the airflow have been ongoing, and are considered as alternative treatments.

Several plants of the Rutaceae family are used in nontraditional medicines around the world. The most common plant is Ruta graveolens $L$ ( $R$. graveolens), popularly known as "Ruta". This plant was brought to Chile from southern Europe. In folk medicines, it has mainly been used for menstrual problems, respiratory diseases, and gastrointestinal disorders $[9,10]$. In several scientific reports, $R$. graveolens has been described to have hypotensive [11], spasmolytic [12], anti-inflammatory [13], sperm motility-inhibitory [14], algaecidal and antifungal [15], and antimicrobial [16] properties, and even to act as an anti-carcinogenic agent [17] and antioxidant [18-20].

Nevertheless, despite the many studies carried out on the biological effects of $R$. graveolens, there are no scientific data about its effects on airway contractility. Thus, as 
part of a research program developed at the Universidad de La Frontera to characterize the bioactive actions of $R$. graveolens, the aim of this study was to perform phytochemical screening of a hydroalcoholic extract of this plant and to evaluate its trachea-relaxant potential on agonist-induced rat tracheal ring contraction.

\section{Results}

\section{Chromatogram analysis and identification of signals}

Our phytochemical screening of the hydroalcoholic extract revealed the presence of secondary metabolites with potential biological effects (quercetin, rutin, and psoralen) (Table 1). Thus, this ethanolic extract was selected for further study.

\section{Airway smooth muscle contraction by carbachol: determination of $\mathrm{EC}_{50}$}

Increasing concentrations of carbachol (0.1-100 $\mu \mathrm{M})$ caused concentration-dependent contraction in tracheal preparations with an $\mathrm{EC}_{50}$ value of $0.2 \mu \mathrm{M}$, reflecting the maximum contraction obtained with $100 \mu \mathrm{M}$ carbachol (Fig. 1).

\section{R. graveolens extract induces relaxation of contracted rat tracheal rings to a similar level to aminophylline}

In the tracheal ring preparations, increasing concentrations of the $R$. graveolens extract $(5,15,30$, and $45 \mu \mathrm{g} / \mathrm{mL})$ significantly reduced $(\mathrm{p}<0.001)$ the muscle tension induced by carbachol in a concentration-dependent manner, with the maximum value of $118 \pm 2.6 \%(n=5)$ obtained at a concentration of $45 \mu \mathrm{g} / \mathrm{mL}$ (EC50: $27.8 \mu \mathrm{g} / \mathrm{mL}$ ) (Fig. 2). Meanwhile, in potassium chloride $(\mathrm{KCl})$ pre-contracted tracheal rings, the muscle tension was reduced by the $R$. graveolens extract $(5-45 \mu \mathrm{g} / \mathrm{mL})$ in a concentration-dependent manner, with the maximum value of $109 \pm 7.9 \%$ obtained at a concentration of 45 $\mu \mathrm{g} / \mathrm{mL}\left(\mathrm{EC}_{50}: 35.5 \mu \mathrm{g} / \mathrm{mL}\right)$ (Fig. 3). The plant extract achieved relaxant effects at a similar level to those of aminophylline. However, the relaxant effects of $R$. graveolens at 5 and $15 \mu \mathrm{g} / \mathrm{mL}$ were significantly lower than those of 0.2 and $0.4 \mathrm{mM}$ aminophylline (Figs. 2 and 3). Aminophylline $(0.2,0.4,0.8$, and $1.0 \mathrm{mM})$ significantly decreased $(\mathrm{p}<0.001)$ the muscle tension induced by carbachol and $\mathrm{KCl}$ in a concentration-dependent manner, with

Table 1 Signal identification

\begin{tabular}{lcll}
\hline $\begin{array}{l}\text { Retention } \\
\text { time (min) }\end{array}$ & Q1 Precursor ions & Q3 Fragment lons & Compounds \\
\hline 19.55 & 187 & $131 / 115$ & Psoralen \\
19.64 & 303 & $229 / 153$ & Quercetin \\
17.70 & 611 & $303 / 465$ & Rutin \\
\hline
\end{tabular}

Identification of the compounds in each sample of the $R$. graveolens extract, analyzed by comparisons with standards in both retention times and fragment settings/specific precursors

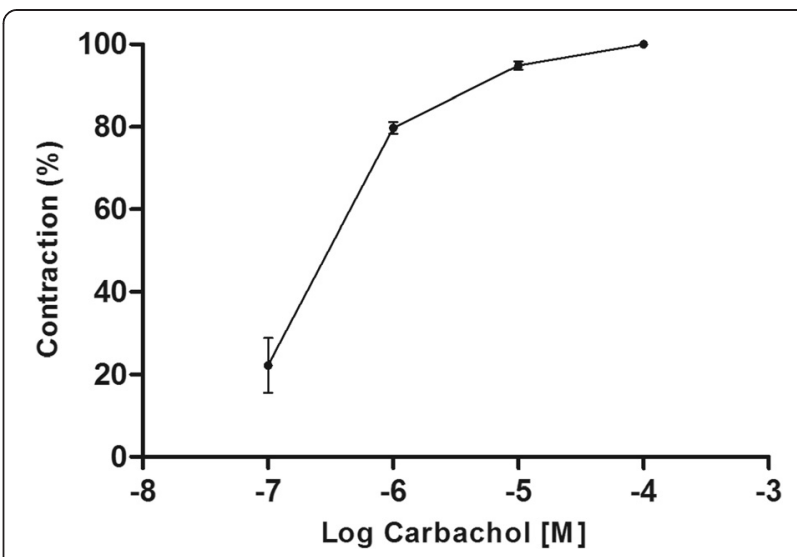

Fig. 1 Dose-response curve of tracheal smooth muscle contraction induced by carbachol $(0.1,1.0,10$, and $100 \mu M)$. Symbols and vertical bars represent means and SEM ( $n=3$ biological replicates)

maximum values of $104 \pm 6.4 \%$ and $106 \pm 5.7 \%$, respectively $\left(\mathrm{EC}_{50}: 6.3 \mu \mathrm{M}\right.$ and $6.0 \mu \mathrm{M}$ for carbachol and $\mathrm{KCl}$, respectively) (Figs. 2 and 3 ).

\section{Antagonist-like effect of the R. graveolens extract against} carbachol-induced tension

To confirm the antagonist-like effect, dose-response curves of carbachol were constructed in the presence of the plant extract or vehicle medium. Pretreatment with the $R$. graveolens extract at 15,30 , and $45 \mu \mathrm{g} / \mathrm{mL}$ for 20 min produced rightward parallel displacement of the carbachol curves and reduced the maximum contraction

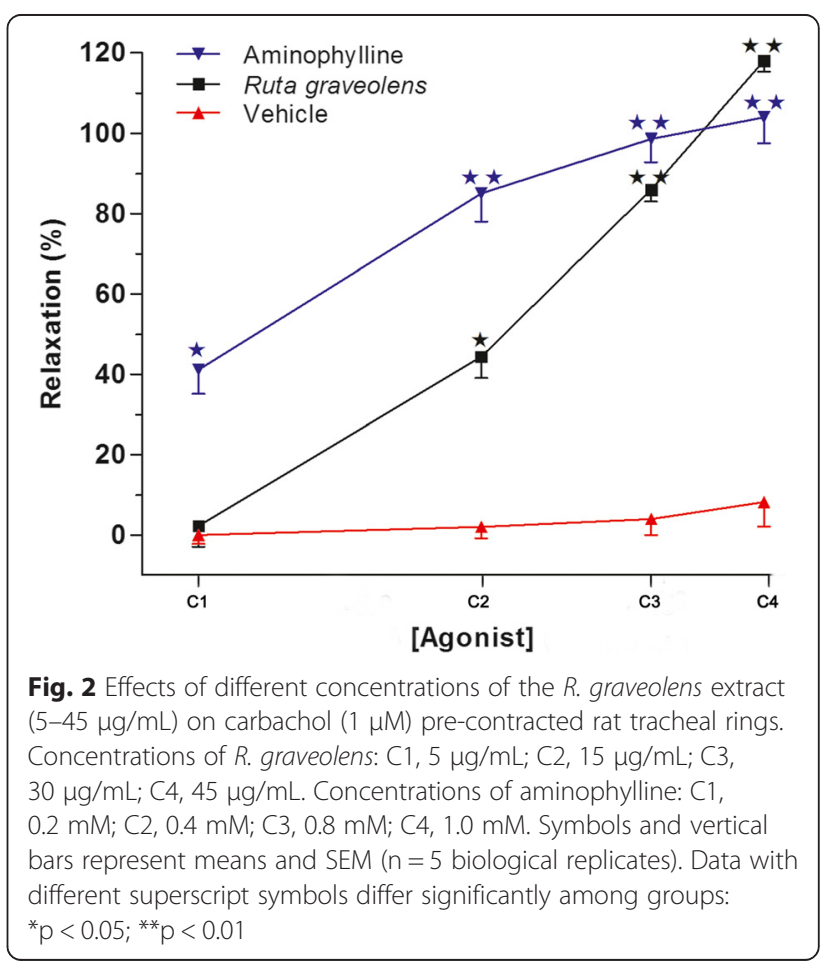




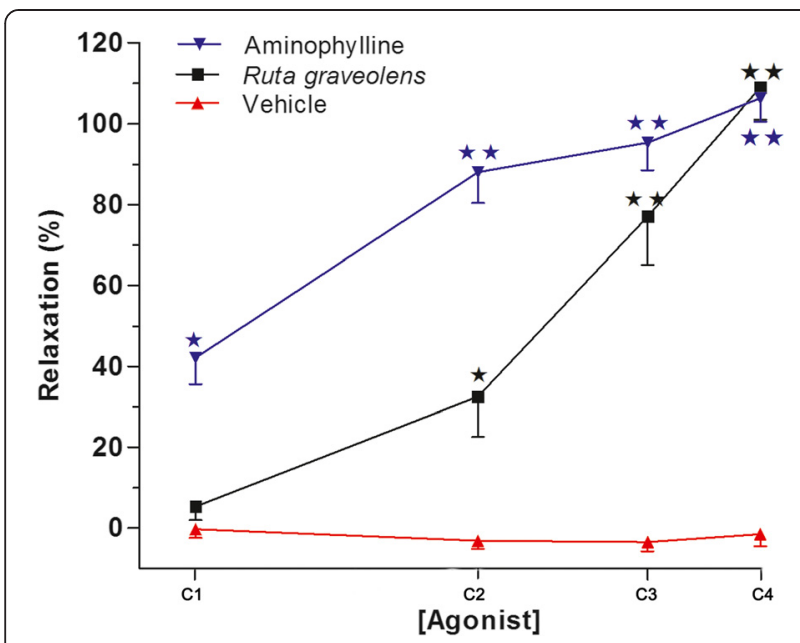

Fig. 3 Effects of different concentrations of the $R$. graveolens extract $(5-45 \mu \mathrm{g} / \mathrm{mL})$ on $\mathrm{KCl}(80 \mathrm{mM})$ pre-contracted rat tracheal rings. Concentrations of $R$. graveolens: C1, $5 \mu \mathrm{g} / \mathrm{mL}$; C2, $15 \mu \mathrm{g} / \mathrm{mL}$; C3, $30 \mu \mathrm{g} / \mathrm{mL} ; C 4,45 \mu \mathrm{g} / \mathrm{mL}$. Concentrations of aminophylline: C1, $0.2 \mathrm{mM}$; C2, 0.4 mM; C3, 0.8 mM; C4, 1.0 mM. Symbols and vertical bars represent means and SEM ( $n=5$ biological replicates). Data with different superscript symbols differ significantly among groups: ${ }^{*} p<0.05 ;{ }^{* *} p<0.01$

to $90.7 \pm 3.0 \%, 88.7 \pm 2.2 \%$, and $64.5 \pm 3.2 \%$, respectively (Fig. 4).

\section{Discussion}

Stimulation of airway calcium-activated potassium channels induces a sustained increase in the intracytoplasmic calcium concentration in smooth muscle cells [21] and is considered to play a significant role in the pathogenic changes associated with asthma [22]. Meanwhile, carbachol induces contraction of the smooth muscle cells by releasing sarcoplasmic calcium, followed by rapid entry

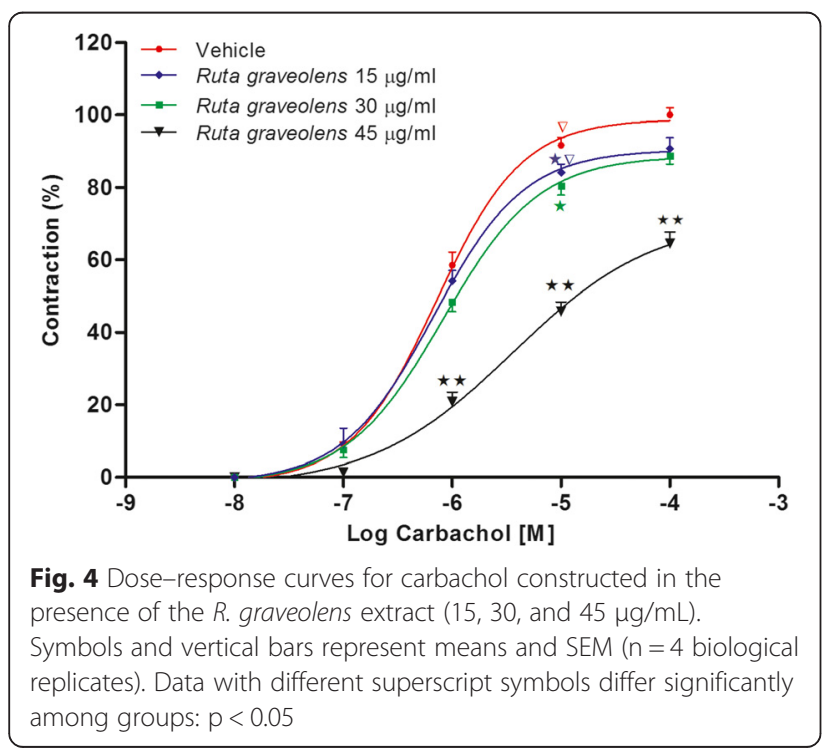

of calcium to the cells [23, 24], thereby stimulating 1,4,5-inositol trisphosphate receptors (IP3Rs) and ryanodine receptors (RyRs) [25], both of which are involved in asthma pathophysiology [26]. In the present study, the $R$. graveolens plant extract was capable of significantly reducing the smooth muscle tension of rat tracheal rings subjected to contraction by a cholinergic agonist (carbachol) and a depolarizing agent $(\mathrm{KCl})$ (Figs. 2 and 3 , respectively). Additionally, our previous report demonstrated the presence of cytotoxic effects with high concentrations only of the $R$. graveolens extract (above $400 \mu \mathrm{g} / \mathrm{mL}$ ) using an endothelial cellular model [27]. Similarly, previous studies have demonstrated myorelaxant effects of plants from the Rutaceae family $[28,29]$. For example, it has been indicated that a hydroalcoholic extract of Ruta chalepensis decreased $\mathrm{KCl}$-induced contraction of the rat ileum, probably by increasing the production of nitric oxide (NO) and cyclic guanosine monophosphate (GMPc) [30]. Other authors have described that benzofurans, acridinons, psoralens, and other coumarins present in plants from the Rutaceae family are able to block potassium currents [31, 32].

Pharmacologically, a competitive antagonist blocks the chain of reactions produced by an agonist, as the antagonist acts on a different site in the receptor within the effector system [33]. Thus, dose-response curves for carbachol $(0.1-100 \mu \mathrm{M})$ were constructed in the presence of the $R$. graveolens extract $(5,10$, and $35 \mu \mathrm{g} / \mathrm{mL}$ ) (Fig. 4). The obtained data suggested that our plant extract acted as a non-competitive antagonist, because as the dose of $R$. graveolens increased, the maximum effect exerted by the cholinergic agonist gradually decreased and produced rightward parallel displacement of the carbachol curves.

Among the chemical components present in the $R$. graveolens extract and likely to be responsible for its proven bioactivity are alkaloids, rutin [34], furanocoumarins (psoralen, xanthotoxin, bergapten) [35], acridone epoxides, acridone glucosides, gravacridondiol, and the greatest alkaloid in $R$. graveolens root, rutacridone [36-39]. Within the active principles described in plants, rutin, a natural flavonoid present in many herb families (Polygonaceae, Rutaceae, and Violaceae), has shown dose-dependent relaxant effects in the rat duodenum [40] and can decrease lipopolysaccharide-induced NO synthesis in vivo [41]. It has been established that a methanolic extract of $R$. graveolens contains approximately $4 \%$ rutin [42]. Another study considered that coumarin compounds of an aqueous extract of $R$. graveolens were probably capable of blocking ionic currents [43]. Our phytochemical screening by liquid chromatography of a hydroalcoholic extract of $R$. graveolens revealed the presence of flavonoids (quercetin and rutin) 
and a furanocoumarin (psoralen), which are probably responsible for the bioactive effects revealed here.

\section{Conclusions}

In conclusion, the main contributions of the present study are the first description of the relaxant effects of $R$. graveolens on rat tracheal smooth muscle and the correlation with its popular use in respiratory diseases. The trachea-relaxant effect can be explained through a noncompetitive antagonistic mechanism, possibly involving the blockade of ionic currents. However, more detailed studies are needed to identify the target of the inhibition, and to determine more precisely the pharmacological mechanisms involved in the observed biological effects.

\section{Methods}

\section{Animals}

All the animals used in the procedures in this study were treated in accordance with international principles and local regulations concerning the care and ethical use of laboratory animals. The experimental protocol was approved by the Bioethical Commission of the University of La Frontera, presented to the Bioethical National Committee in CONICYT, and revised by the FONDEF Committee. Sprague-Dawley rats weighing 200-250 g were used in the experiments and purchased from the Animal Breeding Laboratory of the University of La Frontera. The animals were maintained under controlled environmental conditions, with room temperature at 18-22 ${ }^{\circ} \mathrm{C}$, an alternating $12-\mathrm{h} / 12$-h light/dark cycle, and ad libitum water, and feeding with a standardized pellet.

\section{Drugs and chemicals}

Carbachol, anhydrous aminophylline, and $\mathrm{KCl}$ were acquired from Sigma-Aldrich (USA). The final concentration of $\mathrm{KCl}(80 \mathrm{mM})$ was selected on the basis of previous studies [44, 45].

\section{Extract preparation}

Leaves and aerial parts of $R$. graveolens were collected at Temuco in Southern Chile ( $38^{\circ} 44^{\prime} 52^{\prime \prime} \mathrm{S} ; 72^{\circ} 37^{\prime} 3^{\prime \prime}$ W; $200 \mathrm{~m}$ above sea level). The material was identified by Professor Fernando Romero, Faculty of Medicine, University of La Frontera.

For the purpose of organic extraction, the plant extract was prepared by washing $R$. graveolens leaves with deionized water (Simplicity 185; Millipore, Germany), and drying at $37{ }^{\circ} \mathrm{C}$. The dried leaves were then pulverized, extracted with ethanol/water (4:1) for 3 days, filtered in a vacuum, concentrated in a rotary evaporator, and subjected to lyophilization at $-80{ }^{\circ} \mathrm{C}$ for 2 days (Chris Alpha1-2; Osterade, Germany) to obtain a viscous mass of dark green extract. Just prior to biological testing, the extract was dissolved in vehicle solution (ethanol $0.1 \%$, cremophor $0.1 \%$, dimethylsulfoxide $0.1 \%$, n-hexanol $0.1 \%$ ) to prepare a stock solution of $10 \mathrm{mg} / \mathrm{mL}$.

\section{Phytochemical screening}

The hydroalcoholic freeze-dried $R$. graveolens extract was subjected to phytochemical screening to detect the presence of alkaloids. Briefly, $100 \mathrm{mg}$ of the sample ( $R$. graveolens extract) was dissolved in $4 \mathrm{~mL}$ of methanol, from which a $150-\mu \mathrm{L}$ aliquot was taken for examination on a LC-MS MS system, consisting of a liquid chromatograph (Shimadzu, Japan) connected to MDS Sciex Mass Spectrometer QTRAP 3200 (Applied Biosystems, USA), equipped with an electrospray ionization (ESI) source Turbo $\mathrm{V}^{\mathrm{m} m}$ (AB Sciex, Singapore) at $450{ }^{\circ} \mathrm{C}$. Chromatographic separation was performed with a RP-C18 Column Inertsil ODS-3 $(2.1 \times 150 \mathrm{~mm}, 3 \mathrm{~mm})$ (GL Sciences, USA) using an injection volume of $10 \mu \mathrm{L}$, a flow rate of $0.2 \mathrm{~mL} / \mathrm{min}$, and a column temperature of $35{ }^{\circ} \mathrm{C}$. To separate the standards and samples, a gradient consisting of solvent A (water/acetic acid, 99.9:0.1, v/v), and solvent B (methanol) was applied, followed by a 5 -min equilibration between each sample. Data acquisition was performed using the software Analyst 1.5.1 (Applied Biosystems, USA). The ESI parameters were as follows: Cur gas: $137.9 \mathrm{kPa}$; CAD gas: medium; Gas1: 60 psi; Gas2: 30 psi; capillary voltage: 3500 V. For analysis of samples, the Multiple Reaction Monitoring method was used with three compounds in positive polarity and two transitions for each. The retention times of the standards and their transition precursor ions/fragment ions were considered as the positive identification parameters.

\section{Preparation of isolated trachea and tension measurement} The animals were euthanized by cervical dislocation and their tracheas were removed. The isolated tracheas were dissected, and connective and adipose tissue adhesions were removed. A tracheal segment was cut into transverse rings of $3-5 \mathrm{~mm}$, followed by connection of the lower and upper extremes to a isometric force transducer LabChart pro 6.1 (ADInstruments, CO, USA) in an isolated organ bath with modified Tyrode's solution (in $\mathrm{mM}: \mathrm{NaCl}$ 137; $\mathrm{KCl}$ 5.4; $\mathrm{CaCl}_{2} \cdot 2 \mathrm{H}_{2} \mathrm{O}$ 2.7; $\mathrm{MgCl}_{2} \cdot 6 \mathrm{H}_{2} \mathrm{O} \quad 0.5 ; \mathrm{NaHCO}_{3}$ 11.9; $\mathrm{NaH}_{2} \mathrm{PO}_{4} \cdot \mathrm{H}_{2} \mathrm{O} \quad 0.45$ ) containing $5.55 \mathrm{mM}$ glucose monohydrate. The solution was maintained at $37{ }^{\circ} \mathrm{C}$ and $\mathrm{pH} 7.3$, with constant bubbling of $5 \% \mathrm{CO}_{2}$ and $95 \% \mathrm{O}_{2}$. The tension was continuously measured by the force transducer. To reach spontaneous equilibration, a tension of $1 \mathrm{~g}$ was applied initially for $30 \mathrm{~min}$ [46]. To verify the integrity of the tracheal tissue, $80 \mathrm{mM} \mathrm{KCl}$ was added initially during each experiment, and only responsive tracheal rings were included in the study. 


\section{Determination of $\mathrm{EC}_{50}$ of carbachol}

To determine the $\mathrm{EC}_{50}$ of carbachol, dose-response curves were recorded using increasing concentrations of the reagent $(0.1-100 \mu \mathrm{M})$ starting with the basal tension of the rings at approximately $1 \mathrm{~g}$. Changes in the force transducer were analyzed as the percentage of change in tension from the baseline $(1 \mathrm{~g})$ to the peak of each dose, with approximately 15-min intervals between each treatment.

\section{Determination of R. graveolens effects on contractile activity}

The trachea-relaxant effects of increasing concentrations (C1, $5 \mu \mathrm{g} / \mathrm{mL} ; \mathrm{C} 2,15 \mu \mathrm{g} / \mathrm{mL} ; \mathrm{C} 3,30 \mu \mathrm{g} / \mathrm{mL} ; \mathrm{C} 4,45 \mu \mathrm{g} / \mathrm{mL})$ of the hydroalcoholic extract of $R$. graveolens versus those of anhydrous aminophylline (C1, $0.2 \mathrm{mM}$; C2, 0.4 mM; C3, $0.8 \mathrm{mM}$; C4, $1.0 \mathrm{mM}$ ), as one of the main drugs used to prevent and treat asthma, chronic bronchitis, and other lung diseases [47], were examined. Vehicle $(25 \mu \mathrm{L})$ was used as a negative control. An increase in tone (contraction) was induced with carbachol $(1 \mu \mathrm{M} ; 80 \%$ maximum response obtained) or $\mathrm{KCl}(80 \mathrm{mM})$. In each experiment, the effects of the four increasing concentrations of the extract, aminophylline, or vehicle on the contracted tracheal smooth muscle were measured after exposing the tracheal segment to each concentration of the solution for $15 \mathrm{~min}$. A decrease in tone was considered to be a relaxant effect, and expressed as a positive percentage change in proportion to the maximum contraction.

With the purpose of establishing the possible antagonistic effect of the plant extract, the rings were pre-incubated with 15,30 , and $45 \mu \mathrm{g} / \mathrm{mL}$ of $R$. graveolens extract for at least $20 \mathrm{~min}$ [48] and then induced to contract by adding increasing concentrations of carbachol $(0.1,1.0,10$, and $100 \mu \mathrm{M})$.

\section{Statistical analysis}

The data for the different functional parameters evaluated were expressed as means \pm SEM. Differences between the groups were analyzed by one-way analysis of variance (ANOVA) followed by Tukey multiple comparison tests. Values of $\mathrm{p}<0.05$ were considered to be significant. For the tension analysis, LabChart5.0 was used, with data processing by Origin 6 for the dose-response curves.

\section{Competing interests}

The authors declare that they have no competing interests.

\section{Authors' contributions}

$L A, F R, R S, R R$, and JR were responsible for conducting the experiments, data analysis and interpretation, and preparing the manuscript. KM and JO carried out the plant collection and extraction process, and helped to revise the manuscript. All authors have read and approved the final manuscript.

\section{Acknowledgments}

This work was supported by CONICYT FONDEF-Chile D07I1113. The authors thank the Preclinical Sciences Department, Center of Neuroscience, and
Peptides Biology, Nucleus of Scientific, and Technological Development in Bioresources (BIOREN), Center of Biotechnology on Reproduction Center (CEBIOR), and Center of Genetics, and Immunological Studies (CEGIN), all belonging to the University of La Frontera.

\section{Author details}

${ }^{1}$ Center of Neurosciences and Peptides Biology (CEBIOR-BIOREN), Faculty of Medicine, University of La Frontera, Temuco, Chile. ${ }^{2}$ Center of Genetic and Immunologic Studies (CEGIN), Faculty of Medicine, University of La Frontera, Temuco, Chile. ${ }^{3}$ School of Veterinary Medicine, Unit of Nutrition, and Animal Production, Faculty of Natural Resources, and Veterinary Medicine, Santo Tomás University, Temuco, Chile. ${ }^{4}$ Department of Physiology, Cardiovascular Division, Federal University of Sao Paulo, São Paulo, Brazil.

Received: 5 October 2014 Accepted: 19 May 2015 Published online: 05 June 2015

\section{References}

1. Bousquet J, Jeffery PK, Busse WW, Johnson M, Vignola AM. Asthma. From bronchoconstriction to airways inflammation and remodeling. Am J Respir Crit Care Med. 2000;161:1720-45.

2. Bergeron C, Tulic MK, Hamid Q. Airway remodelling in asthma: from benchside to clinical practice. Can Respir J. 2010;17:e85-93.

3. Fabbri LM, Romagnoli M, Corbetta L, Casoni G, Busljetic K, Turato G, et al, Differences in airway inflammation in patients with fixed airflow obstruction due to asthma or chronic obstructive pulmonary disease. Am J Respir Crit Care Med. 2003;167:418-24.

4. Barnes PJ, Shapiro SD, Pauwels RA. Chronic obstructive pulmonary disease: molecular and cellular mechanisms. Eur Respir J. 2003;22:672-88.

5. Janssen $\sqcup$, Killian K. Airway smooth muscle as a target of asthma therapy: history and new directions. Respir Res. 2006;7:123.

6. Liu B, Yang J, Wen Q, Li Y. Isoliquiritigenin, a flavonoid from licorice, relaxes guinea-pig tracheal smooth muscle in vitro and in vivo: role of cGMP/PKG pathway. Eur J Pharmacol. 2008;587:257-66.

7. Groneberg DA, Chung KF. Models of chronic obstructive pulmonary disease. Respir Res. 2004;5:18.

8. Xu Y, Zhang Y, Cardell LO. Nicotine enhances murine airway contractile responses to kinin receptor agonists via activation of JNK- and PDE4-related intracellular pathways. Respir Res. 2010;11:13.

9. Pollio A, De Natale A, Appetiti E, Aliotta G, Touwaide A. Continuity and change in the Mediterranean medical tradition: Ruta spp. (rutaceae) in Hippocratic medicine and present practices. J Ethnopharmacol. 2008;116:469-82

10. Miguel E. Rue (Ruta L., Rutaceae) in traditional Spain: Frequency and distribution of its medicinal and symbolic applications. Economic Botany. 2003:57:231-44.

11. Chen C, Wang R, Zhou S, Zhao J, Xu Y. Effects of Mitochondrial ATPSensitive Potassium Channels on the Proliferation and Secretion of Human Airway Smooth Muscle Cells. Iran J Allergy Asthma Immunol. 2014;13:420-7.

12. Van Der Velden J, Sum G, Barker D, Koumoundouros E, Barcham G, Wulff H, et al. K(Ca)3.1 channel-blockade attenuates airway pathophysiology in a sheep model of chronic asthma. PLoS One. 2013;8:e66886.

13. Raghav SK, Gupta B, Shrivastava A, Das HR. Inhibition of lipopolysaccharideinducible nitric oxide synthase and IL-1beta through suppression of NF-kappaB activation by 3-(1'-1'-dimethyl-allyl)-6-hydroxy-7-methoxy-coumarin isolated from Ruta graveolens L. Eur J Pharmacol. 2007;560:69-80.

14. Harat ZN, Sadeghi MR, Sadeghipour HR, Kamalinejad M, Eshraghian MR. Immobilization effect of Ruta graveolens $L$. on human sperm: a new hope for male contraception. J Ethnopharmacol. 2008;115:36-41.

15. Meepagala KM, Schrader KK, Wedge DE, Duke SO. Algicidal and antifungal compounds from the roots of Ruta graveolens and synthesis of their analogs. Phytochemistry. 2005;66:2689-95.

16. Ojala T, Remes S, Haansuu P, Vuorela H, Hiltunen R, Haahtela K, et al. Antimicrobial activity of some coumarin containing herbal plants growing in Finland. J Ethnopharmacol. 2000;73:299-305.

17. Preethi KC, Kuttan G, Kuttan R. Anti-tumour activity of Ruta graveolens extract. Asian Pac J Cancer Prev. 2006;7:439-43.

18. Piao XL, Park IH, Baek SH, Kim HY, Park MK, Park JH. Antioxidative activity of furanocoumarins isolated from Angelicae dahuricae. J Ethnopharmacol. 2004;93:243-6. 
19. Ratheesh M, Shyni GL, Helen A. Methanolic extract of Ruta graveolens L. inhibits inflammation and oxidative stress in adjuvant induced model of arthritis in rats. Inflammopharmacology. 2009;17:100-5.

20. Ratheesh M, Shyni GL, Sindhu G, Helen A. Inhibitory effect of Ruta graveolens $\mathrm{L}$. on oxidative damage, inflammation and aortic pathology in hypercholesteromic rats. Exp Toxicol Pathol. 2011;63:285-90.

21. Liu B, Peel SE, Fox J, Hall IP. Reverse mode Na+/Ca2+ exchange mediated by STIM1 contributes to $\mathrm{Ca} 2+$ influx in airway smooth muscle following agonist stimulation. Respir Res. 2010;11:168.

22. Kocmalova M, Oravec M, Adamkov M, Sadlonova V, Kazimierova I, Medvedova I, et al. Potassium ion channels and allergic asthma. Adv Exp Med Biol. 2015;838:35-45.

23. Pacaud $\mathrm{P}$, Bolton TB. Relation between muscarinic receptor cationic current and internal calcium in guinea-pig jejunal smooth muscle cells. J Physiol. 1991;441:477-99.

24. Wayman CP, McFadzean I, Gibson A, Tucker JF. Cellular mechanisms underlying carbachol-induced oscillations of calcium-dependent membrane current in smooth muscle cells from mouse anococcygeus. Br J Pharmacol. 1997;121:1301-8.

25. White C, McGeown G. Carbachol triggers RyR-dependent Ca2+ release via activation of IP3 receptors in isolated rat gastric myocytes. J Physiol. 2002;542:725-33.

26. Du W, Stiber JA, Rosenberg PB, Meissner G, Eu JP. Ryanodine receptors in muscarinic receptor-mediated bronchoconstriction. J Biol Chem. 2005;280:26287-94.

27. Fernández I, Gómez P, Parodi J, Mejía F, Salazar R. Chilean crude extract of Ruta graveolens generates vasodilatation in rat aorta at subtoxic cellular concentrations. Adv Biosci Biotechnol. 2013;4:29-36.

28. Moazedi A, Dabir N, Naseri G, Zadkarami M. The Role of Opioid and a-adrenergic Receptors in the lleal Antispasmodic Activity of Ruta chalepensis Extract. J Biol Sci. 2010;10:779-84.

29. Grigorjev CA. Brizuela NY: [Effects of ruta SSP on the activity of the smooth gastrointestinal muscle isolated of rat]. Rev Fac Cien Med Univ Nac Cordoba. 2010;67:77-80.

30. Moazedi AA, Dabir N, Naseri MK, Zadkarami MR. The role of NO and CGMP in antispasmodic activity of Ruta chalepensis leaf extract on rat ileum. Pak J Biol Sci. 2010;13:83-7.

31. Bethge EW, Bohuslavizki KH, Hansel W, Kneip A, Koppenhofer E. Effects of some potassium channel blockers on the ionic currents in myelinated nerve. Gen Physiol Biophys. 1991;10:225-44.

32. Bohuslavizki KH, Hansel W, Kneip A, Koppenhofer E, Reimers A. Potassium channel blockers from Ruta-a new approach for the treatment of multiple sclerosis. Gen Physiol Biophys. 1992;11:507-12.

33. Botana L, Landoni F, Martín-Jimenez T. Farmacología y Terapéutica Veterinaria. 2a Edición edn. Madrid: McGraw-Hill Interamericana; 2002.

34. Pirouzpanah S, Rashidi MR, Delazar A, Razavieh SV, Hamidi A. Inhibitory effects of Ruta graveolens L. extract on guinea pig liver aldehyde oxidase. Chem Pharm Bull (Tokyo). 2006;54:9-13.

35. Diwan R, Malpathak N. Furanocoumarins: novel topoisomerase I inhibitors from Ruta graveolens L. Bioorg Med Chem. 2009;17:7052-5.

36. Kuzovkina I, Al'terman I, Schneider B. Specific accumulation and revised structures of acridone alkaloid glucosides in the tips of transformed roots of Ruta graveolens. Phytochemistry. 2004;65:1095-100.

37. Bertrand C, Fabre N, Moulis C. A new coumarin glucoside, coumarins and alkaloids from Ruta corsica roots. Fitoterapia. 2004;75:242-4.

38. Kostova I, Ivanova A, Mikhova B, Klaiber I. Alkaloids and Coumarins from Ruta graveolens. J Math Chem. 1999;130:703-7.

39. Sidwa-Gorycka M, Królicka A, Kozyra M, Głowniak K, Bourgaud F, Łojkowska E. Establishment of a co-culture of Ammi majus L. and Ruta graveolens $L$. for the synthesis of furanocoumarins. Plant Science. 2003;165:1315-9.

40. Altinkurt O, Öztürk Y. Effect of rutin on the isolated rat duodenum and comparison with the effects of adrenaline, isoprenaline and papaverine. J Fac Pharm Ankara. 1987;17:49-55.

41. Chen YC, Shen SC, Lee WR, Hou WC, Yang LL, Lee TJ. Inhibition of nitric oxide synthase inhibitors and lipopolysaccharide induced inducible NOS and cyclooxygenase-2 gene expressions by rutin, quercetin, and quercetin pentaacetate in RAW 264.7 macrophages. J Cell Biochem. 2001;82:537-48.

42. Raghav SK, Gupta B, Agrawal C, Goswami K, Das HR. Anti-inflammatory effect of Ruta graveolens $L$. in murine macrophage cells. J Ethnopharmacol. 2006;104:234-9.
43. Harat ZN, Lakpour N, Sadeghipoor HR, Kamalinejad M, Eshraghian MR, Naghibi B, et al. Immobilising effect of Ruta graveolens L. on human spermatozoa: coumarin compounds are involved. Andrologia. 2015.

44. Cevit O, Bagcivan I, Sarac B, Parlak A, Durmus N, Kaya T. Mechanism of relaxation induced by nicotine in normal and ovalbumin-sensitized guinea-pig trachea. Eur J Pharmacol. 2007:567:149-54.

45. Toque HA, Monica FZ, Morganti RP, De Nucci G, Antunes E. Mechanisms of relaxant activity of the nitric oxide-independent soluble guanylyl cyclase stimulator BAY 41-2272 in rat tracheal smooth muscle. Eur J Pharmacol. 2010;645:158-64.

46. de Sousa AA, Soares PM, de Almeida AN, Maia AR, de Souza EP, Assreuy AM. Antispasmodic effect of Mentha piperita essential oil on tracheal smooth muscle of rats. J Ethnopharmacol. 2010;130:433-6.

47. Singhi S, Grover S, Bansal A, Chopra K. Randomised comparison of intravenous magnesium sulphate, terbutaline and aminophylline for children with acute severe asthma. Acta Paediatr. 2014;103:1301-6.

48. Vieira AB, Coelho LP, Insuela DB, Carvalho VF, dos Santos MH, Silva PM, et al. Mangiferin prevents guinea pig tracheal contraction via activation of the nitric oxide-cyclic GMP pathway. PLoS One. 2013;8, e71759.

\section{Submit your next manuscript to BioMed Central and take full advantage of:}

- Convenient online submission

- Thorough peer review

- No space constraints or color figure charges

- Immediate publication on acceptance

- Inclusion in PubMed, CAS, Scopus and Google Scholar

- Research which is freely available for redistribution 